\title{
Intrasubject variability of pulmonary function testing in healthy children
}

\author{
ARLENE A HUTCHISON, ANNA ERBEN, LOUISE A McLENNAN, LOUIS I LANDAU, \\ AND PETER D PHELAN
}

From the Department of Thoracic Medicine, Royal Children's Hospital, Melbourne, Australia

\begin{abstract}
The intrasubject variability of repeat pulmonary function testing was examined in 20 healthy children aged 10 to 16 years. The children were tested a maximum of 11 times over a period of two months. The tests examined were spirometry, maximum expiratory flow-volume curves, body plethysmograph determination of lung volumes, and single breath nitrogen washout. The time of day or the length of the re-test interval, up to a period of two months, did not significantly affect the variability. Standard deviation was used when comparing the variability of measurements with the same units and coefficient of variation was used when comparing measurements of different units. The vital capacity measured by spirometry was the least variable measurement. Functional residual capacity, residual volume and total lung capacity were equally reproducible but as a group were more variable than vital capacity. There was no significant difference between the variability of the following measurements: forced expired flow from 25 to $75 \%$ of the vital capacity, flows at $70 \%, 50 \%$ and $40 \%$ total lung capacity, and flows at $50 \%$ vital capacity. Flows at $25 \%$ vital capacity were significantly less variable than other measurements of flow. The variability of forced expired volume in one second was examined and the use of this measurement in determining significant bronchial hyper-reactivity was assessed.
\end{abstract}

Serial pulmonary function testing is used in children with chest disease to determine the progression of their disease or the response to therapy. However, before a particular change in sequential measurements can be attributed to the disease it is essential to know the degree of variability caused by repeat testing alone. In adults the intrasubject variability of maximum expiratory flow volume (MEFV) curves has been attributed to oscillations in flow and inadequate inspiratory volume with minimal variability caused by effort or the time the test was performed. ${ }^{1-3}$ Single breath nitrogen washout (SBNW) has also been examined in adults and the slope of phase III has been shown to be affected by inspiratory and expiratory flow rates, volume history, and even the type of undergarment worn. ${ }^{4-6}$

The purpose of this study was to examine the degree of intrasubject variability for pulmonary function testing in healthy children. Variability resulting from the time of day or the length of the re-1est interval was assessed. Because asthma and cystic fibrosis are the major causes of chronic lung disease in children, the tests of particular interest were those that indicate airways disease. For this reason the tests examined were spirometry, single breath nitrogen washout, body plethysmograph determination of lung volumes, and maximum expiratory flow volume curves.

\section{Methods}

Healthy subjects were selected from a group of volunteer schoolchildren. To qualify for the study the child had to conform to the following criteria: no history of wheeze, cough for more than one week, hay fever or eczema; no upper respiratory tract infection in the two weeks before any study; no parent or sibling with asthma, bronchitis, chronic cough, hay fever, or eczema; no history of smoking more than three cigarettes per week at any time; no medications taken during the study; and height and weight between the 10th and 90th percentile for age. 
Using these criteria 20 healthy subjects, 11 females and nine males aged 10 to 16 years were selected.

Each subject was studied a maximum of 11 times. Each study consisted of spirometry, body plethysmograph determination of lung volumes and flow volume curves, and single breath nitrogen washout. The same three persons (AE, AH, LM) administered all tests.

The studies were performed according to the following schedule:

$\begin{array}{llll}\text { Day } 1 & 9 \mathrm{am} & 11 \mathrm{am} & 4 \mathrm{pm} \\ \text { Day } 3 & & & 4 \mathrm{pm} \\ \text { Day } 4 & 9 \mathrm{am} & 11 \mathrm{am} & 4 \mathrm{pm} \\ \text { Day } 8 & & & 4 \mathrm{pm} \\ \text { Day } 15 & & & 4 \mathrm{pm} \\ \text { Day 29 } & & & 4 \mathrm{pm} \\ \text { Day } 57 & & & 4 \mathrm{pm}\end{array}$

The first three days of the schedule with its frequent measurements were followed strictly. Thereafter, if the child had a previous school commitment an alternative day was used which was within a few days of the intended schedule. Nine children attended for the complete 11 sessions, six children for 10 sessions, one child for nine sessions, three children for eight sessions, and one child for seven. If the child had a cold during the study no tests were performed until a full two weeks had elapsed after the end of symptoms. Three children developed an upper respiratory tract infection during the study but none had an associated cough.

Spirometry was performed in the seated position using a Godart nine-litre expirograph according to a recommended standard technique. ${ }^{7}$ Vital capacity (VCsp), forced expired volume in one second $\left(\mathrm{FEV}_{1}\right)$, and average forced expiratory flow from $25 \%$ to $75 \%$ of the vital capacity (FEF 25-75\%) were calculated and corrected for BTPS.

A constant pressure integrated flow plethysmograph was used to record the maximum expiratory flow volume curve and lung volumes. The child was seated in the plethysmograph and allowed to assume tidal breathing. After a maximum inspiration, forced expiratory flow was measured at the mouth using a Fleisch no 4 pneumotachograph and plotted on the $Y$ axis of a Tektronix 554B storage oscilloscope, while expired volume was plotted simultaneously on the $\mathrm{X}$ axis. The MEFV curve was photographed. This manoeuvre was repeated until a maximum effort was obtained. Using the photograph with the best effort, forced vital capacity (VC flow) was measured from the plethysmograph volume change and flows at $50 \%$ vital capacity (Vmax VC 50) and $25 \%$ vital capacity (Vmax VC 25) were calculated and expressed as litres/s and as $\mathrm{VC} / \mathrm{s}$. The flow rates were also calculated at $70 \%, 50 \%$ and $40 \%$ of TLC (Vmax TLC 70, Vmax TLC 50, Vmax TLC 40) and expressed as litres/s and TLC/s.

Using the method of DuBois, ${ }^{8}$ thoracic gas volume at functional residual capacity (FRC) was determined and residual volume (RV) calculated by subtracting expiratory reserve volume, total lung capacity (TLC) calculated by adding inspiratory capacity, and VC calculated by subtracting RV from TLC (VC TLC-RV). The procedure was repeated until the child performed at least two manoeuvres with consistent results.

The single breath nitrogen washout (SBNW) was measured in the seated position using the method of Anthonisen et al. ${ }^{9}$ After a stabilisation period the subject was asked to expire completely to RV. This was followed by an inspiration of $100 \%$ oxygen to TLC. The subject then expired slowly at a constant rate of $0.2-0.31 / \mathrm{s}$. This was achieved by displaying the expiratory flow rate (measured with a no 3 Fleisch pneumotachograph) on an oscilloscope. The nitrogen concentration in the expired gas was measured continuously with a Hewlett Packard Nitrogen Analyser and plotted on the $\mathrm{Y}$ axis of an $\mathrm{X}-\mathrm{Y}$ recorder. Expired volume was calculated by integrating the flow rate measured with the Fleisch pneumotachograph and was simultaneously plotted on the $\mathrm{X}$ axis. The test was repeated until two reproducible graphs were obtained with the vital capacities agreeing within $5 \%$. The slope of phase III was calculated by drawing a line of best fit through the points of phase III on the two graphs and then determining the mean slope.

\section{Statistical methods and results}

The table contains a summary of a representative sample of the within-subject means and standard deviations (SDs). Values for SD were rounded off for ease of presentation only.

\section{ANALYSIS OF VARIANCE}

For the analysis of variance spirometric measurements and body plethysmographic lung volumes were expressed as percent of predicted normal, ${ }^{10} 11$ and flows at various points of the MEFV curves expressed as TLC/s or VC/s in order to minimise between-subject differences. For each measurement of lung function the within-day effect was assessed using a one-way analysis of variance for samples of uneven sizes ${ }^{12}$ which compared the 
Table Mean of repeat measurements for each subject $\pm 1 S D$

\begin{tabular}{|c|c|c|c|c|c|c|c|c|c|c|}
\hline $\begin{array}{l}\text { Subject } \\
\text { number }\end{array}$ & $\begin{array}{l}\text { Age } \\
(y r)\end{array}$ & Sex & $\begin{array}{l}V C s p \\
(l)\end{array}$ & $\begin{array}{l}F E V_{1} \\
(l)\end{array}$ & $\begin{array}{l}F E F 25-75 \% \\
(l)\end{array}$ & $\begin{array}{l}R V \\
(l)\end{array}$ & $\begin{array}{l}T L C \\
(l)\end{array}$ & $\begin{array}{l}V \max T L C 50 \\
T L C / s\end{array}$ & $\begin{array}{l}V \max V C 25 \\
V C / s\end{array}$ & $\begin{array}{l}\text { SBNW } \\
\text { Slope III }\end{array}$ \\
\hline 1 & 11 & $\mathbf{F}$ & $2 \cdot 5 \pm 0 \cdot 13$ & $2 \cdot 2 \pm 0.19$ & $2.8 \pm 0.58$ & $1 \cdot 3 \pm 0 \cdot 15$ & $3 \cdot 6+0 \cdot 21$ & $0.43+0.17$ & $0.54 \pm 0.09$ & $1.20 \pm 0.09$ \\
\hline 2 & 12 & $\mathbf{F}$ & $2.9 \pm 0.05$ & $2.5 \pm 0.06$ & $3 \cdot 4 \pm 0.21$ & $0.7 \pm 0.19$ & $3.7 \pm 0.09$ & $0.56 \pm 0.11$ & $0.45 \pm 0.06$ & $0.65 \pm 0.26$ \\
\hline 3 & 12 & F & $2 \cdot 3 \pm 0 \cdot 11$ & $2 \cdot 0 \pm 0.12$ & $2.9 \pm 0.20$ & $0 \cdot 7 \pm 0 \cdot 18$ & $3 \cdot 2 \pm 0 \cdot 14$ & $0 \cdot 61 \pm 0 \cdot 11$ & $0.55 \pm 0.07$ & $0.75 \pm 0.16$ \\
\hline 4 & 12 & $\mathbf{F}$ & $2.1 \pm 0.06$ & $1.9 \pm 0.06$ & $2.9 \pm 0.29$ & $0.7 \pm 0.12$ & $2 \cdot 7 \pm 0 \cdot 10$ & $0.76 \pm 0.13$ & $0.75 \pm 0.11$ & $1.70 \pm 0.27$ \\
\hline 5 & 12 & F & $3 \cdot 6 \pm 0 \cdot 11$ & $2.9 \pm 0.19$ & $3.6 \pm 0.71$ & $1 \cdot 0 \pm 0 \cdot 17$ & $4.9 \pm 0.20$ & $0.59 \pm 0.12$ & $0.48 \pm 0.07$ & $0.69 \pm 0.23$ \\
\hline 6 & 13 & $\mathrm{~F}$ & $3.3 \pm 0.07$ & $2.9 \pm 0.06$ & $3.3 \pm 0.29$ & $0.9 \pm 0 \cdot 14$ & $4 \cdot 3 \pm 0.17$ & $0.52 \pm 0.05$ & $0.44 \pm 0.05$ & $0.60 \pm 0.30$ \\
\hline 7 & 14 & $\mathbf{F}$ & $2.6 \pm 0.05$ & $2 \cdot 3 \pm 0.04$ & $3.7 \pm 0.26$ & $0.8 \pm 0.13$ & $3 \cdot 5 \pm 0 \cdot 11$ & $0.61 \pm 0.08$ & $0.46 \pm 0.09$ & $1 \cdot 10 \pm 0 \cdot 20$ \\
\hline 8 & 14 & $\mathbf{F}$ & $4.3 \pm 0.08$ & $3 \cdot 7 \pm 0 \cdot 10$ & $4 \cdot 5 \pm 0 \cdot 14$ & $1 \cdot 1 \pm 0 \cdot 25$ & $5 \cdot 7 \pm 0 \cdot 29$ & $0.58 \pm 0.09$ & $0.48 \pm 0.04$ & $0.95 \pm 0.05$ \\
\hline 9 & 15 & $\mathbf{F}$ & $3.6 \pm 0.05$ & $3 \cdot 1 \pm 0 \cdot 10$ & $3 \cdot 5 \pm 0 \cdot 34$ & $0.9 \pm 0.09$ & $4.6 \pm 0.09$ & $0 \cdot 61 \pm 0 \cdot 10$ & $0.57 \pm 0.06$ & $0.62 \pm 0.20$ \\
\hline 10 & 15 & $\mathbf{F}$ & $3.9 \pm 0.05$ & $3 \cdot 3 \pm 0 \cdot 14$ & $3.7 \pm 0.49$ & $0.9 \pm 0.14$ & $5 \cdot 3 \pm 0 \cdot 14$ & $0.58 \pm 0.09$ & $0.52 \pm 0 \cdot 11$ & $0.73 \pm 0.19$ \\
\hline 11 & 15 & F & $3 \cdot 3 \pm 0 \cdot 17$ & $2.9 \pm 0.09$ & $3 \cdot 6 \pm 0 \cdot 19$ & $0.9 \pm 0.26$ & $4.4 \pm 0.26$ & $0.65 \pm 0.13$ & $0.49 \pm 0.05$ & $0.72 \pm 0.17$ \\
\hline 12 & 10 & $\mathbf{M}$ & $2.5 \pm 0.07$ & $2 \cdot 1 \pm 0 \cdot 14$ & $2 \cdot 3 \pm 0.33$ & $0.9 \pm 0.12$ & $3 \cdot 4 \pm 0 \cdot 18$ & $0 \cdot 45 \pm 0 \cdot 10$ & $0.41 \pm 0.06$ & $1.20 \pm 0 \cdot 16$ \\
\hline 13 & 11 & $\mathbf{M}$ & $2.4 \pm 0.07$ & $1.9 \pm 0 \cdot 15$ & $2 \cdot 1 \pm 0.54$ & $0.8 \pm 0.10$ & $3 \cdot 3 \pm 0 \cdot 10$ & $0.47 \pm 0.06$ & $0.42 \pm 0.08$ & $0.69 \pm 0.14$ \\
\hline 14 & 13 & $\mathbf{M}$ & $3.6 \pm 0.07$ & $2 \cdot 9 \pm 0 \cdot 10$ & $2 \cdot 7 \pm 0 \cdot 15$ & $1 \cdot 0 \pm 0.23$ & $4.6 \pm 0.23$ & $0.47 \pm 0.07$ & $0.43 \pm 0.04$ & $0.89 \pm 0.24$ \\
\hline 15 & 13 & $\mathbf{M}$ & $2.8 \pm 0.09$ & $2.4 \pm 0.08$ & $2 \cdot 6 \pm 0 \cdot 16$ & - & - & - & $0.46 \pm 0.06$ & $0.73 \pm 0.20$ \\
\hline 16 & 14 & $\mathbf{M}$ & $4.8 \pm 0.06$ & $4 \cdot 0 \pm 0 \cdot 10$ & $3 \cdot 9 \pm 0 \cdot 16$ & $1 \cdot 2 \pm 0 \cdot 11$ & $6 \cdot 1 \pm 0 \cdot 14$ & $0.53 \pm 0.05$ & $0.42 \pm 0.04$ & $0.47 \pm 0.08$ \\
\hline 17 & 15 & $\mathbf{M}$ & $4 \cdot 4 \pm 0 \cdot 13$ & $3.5 \pm 0.08$ & $3 \cdot 3 \pm 0 \cdot 10$ & $1.4 \pm 0.12$ & $6 \cdot 0 \pm 0 \cdot 14$ & $0.38 \pm 0.03$ & $0.37 \pm 0.04$ & $0.87 \pm 0.13$ \\
\hline 18 & 15 & M & $4.1 \pm 0.07$ & $3 \cdot 3 \pm 0 \cdot 13$ & $3.9 \pm 0.63$ & $1.3 \pm 0.63$ & $5 \cdot 4 \pm 0 \cdot 30$ & $0.55 \pm 0.13$ & $0.49 \pm 0.08$ & $0.44 \pm 0.15$ \\
\hline 19 & 15 & M & $4.0 \pm 0.06$ & $3 \cdot 7 \pm 0.08$ & $4.8 \pm 0.35$ & $1 \cdot 2 \pm 0.26$ & $5 \cdot 3 \pm 0.29$ & $0.74 \pm 0.12$ & $0.82 \pm 0.07$ & $0.86 \pm 0.17$ \\
\hline 20 & 16 & $\mathbf{M}$ & $4 \cdot 5 \pm 0.12$ & $3.8 \pm 0.09$ & $4 \cdot 1 \pm 0 \cdot 19$ & $1 \cdot 5 \pm 0.37$ & $6.3+0.31$ & $0.47 \pm 0.07$ & $0.47 \pm 0.04$ & $0.51 \pm 0.20$ \\
\hline
\end{tabular}

mean values at each time during the day. There were no significant differences detected between $9 \mathrm{am}, 11 \mathrm{am}$, and $4 \mathrm{pm}$ measurements. Similarly, a second one-way analysis of variance was performed to assess the day-to-day effect. For each measurement the seven repeat determinations taken at $4 \mathrm{pm}$ were compared and there were no significant differences in the means.

The analyses of variance showed that there was no significant difference in the mean value of each measurement tested for the 20 subjects during the day and from day to day. To assess if the time period between re-testing affected the degree of variability, the short-term variability was compared with the long-term variability. Short-term variability was defined as the coefficient of variation $[\mathrm{CV} \%=(\mathrm{SD} /$ mean $) \times 100 \%]$ for the seven measurements made on days 1,3 , and 4 and the long-term variability as the $\mathrm{CV} \%$ of the seven measurements taken at $4 \mathrm{pm}$ (days $1,3,4,8,15$,

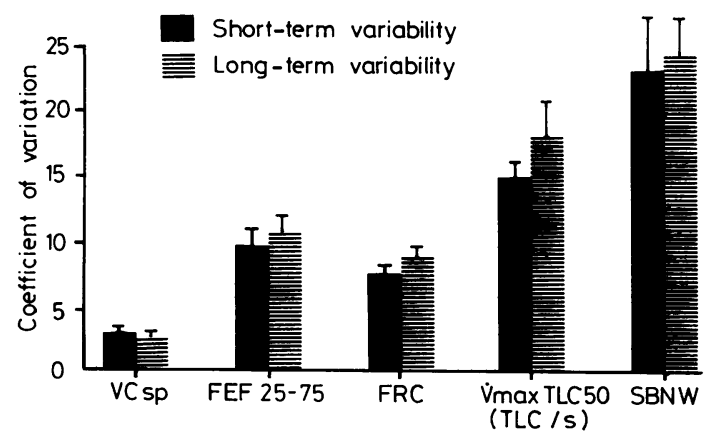

Fig 1 Comparison of short-term versus long-term CV \% showing no significant difference.
$29,57)$. For each parameter the short-term $\mathrm{CV} \%$ was compared to the long-term $\mathrm{CV} \%$ using a Wilcoxon signed rank test. There was no significant difference between the short-term and the long-term $\mathrm{CV} \%$ (fig 1).

\section{COMPARING THE DEGREE OF VARIABILITY}

The Wilcoxon signed rank test was used to compare SDs between measurements with the same units to determine which tests were more variable.

Comparing parameters with the units of volume (fig 2), VCsp had the lowest SDs, FEV 1 and VC flow were slightly but significantly more variable-that is, higher SDs than VCsp $(p<0.05)$ and VCTLC-RV was significantly more variable than both VC flow $(\mathrm{p}<0.05)$ and VC sp $(\mathrm{p}<0 \cdot 01)$. All three measurements of $\mathrm{VC}$ had significantly lower SDs than TLC, FRC, and RV. However, these latter three measurements showed the same degree of variability.

There was no significant difference between the SDs for FEF $25-75 \%$, Vmax TLC 70, Vmax TLC 50, Vmax TLC 40, and Vmax VC 50 (fig 3). The SDs for Vmax VC 25 were significantly less than the other measurements of flow.

Comparison of the measurements of different units was attempted using the coefficient of variation (fig 4). In general, spirometric volume measurements had lower $\mathrm{CV} \%$, flows at various portions of the MEFV curve higher $\mathrm{CV} \%$, and SBNW had the highest $\mathrm{CV} \%$. The total group number was too small to allow division into different ages or sexes so the influence of these factors on the degree of reproducibility could not be examined. 


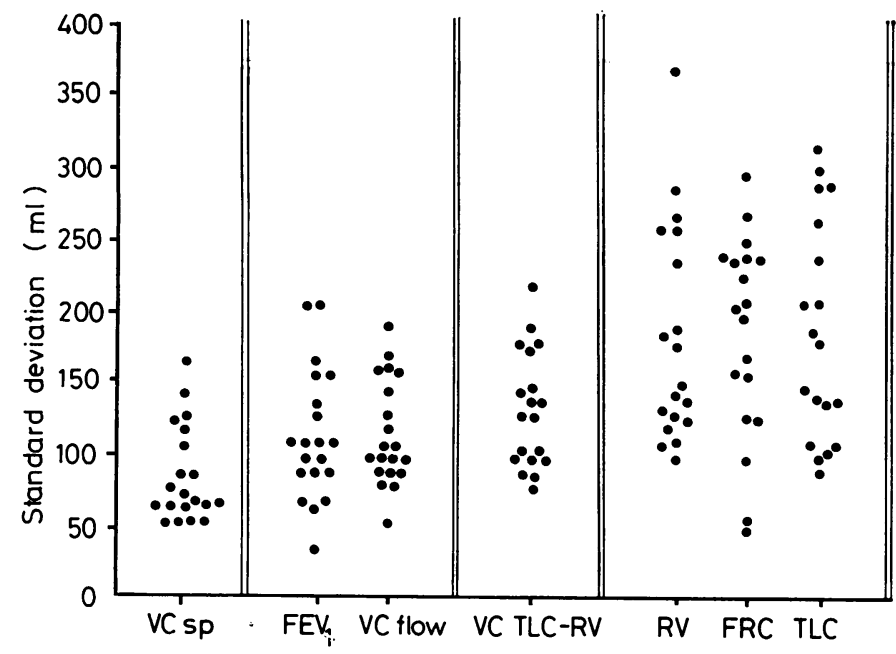

Fig 2 Each point represents the standard deviation for one subject for repeated measurements. Tests are arranged in order of increasing $S D$ and are placed in four groups. Within a group there is no significant difference in the SD but between groups there are significant differences $(p<0.05)$.

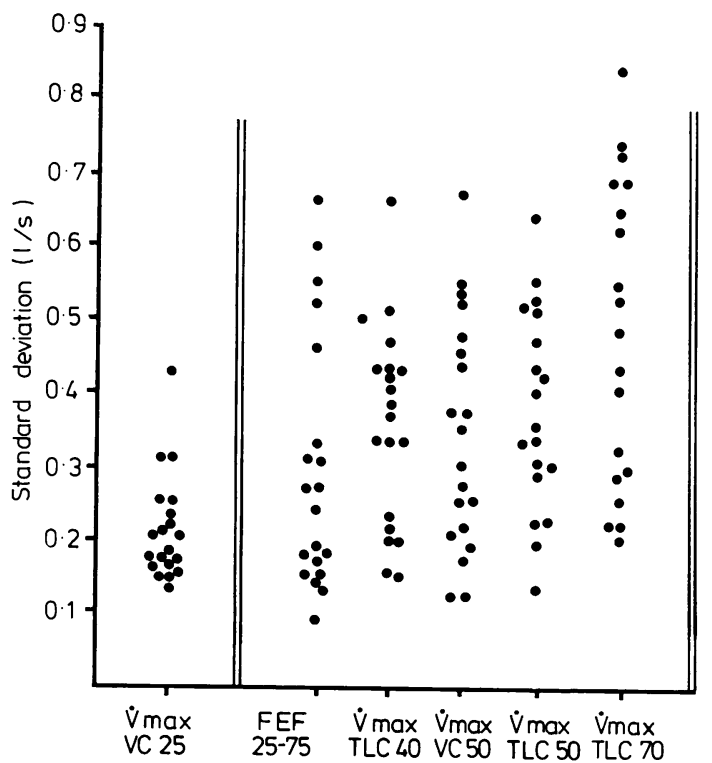

Fig 3 Each point represents the standard deviation for one subject for repeated measurements. Tests are arranged in order of increasing $S D$ and are placed in two groups. Within a group there is no significant difference in the SD but between groups there are significant differences $(p<0.05)$.

\section{RANK CORRELATION COEFFICIENTS}

Many Spearman rank correlation coefficients $\left(r^{\prime}\right)$ using SDs were calculated. A significant positive rank correlation indicated that a child who was more variable on one test was significantly more variable on the other. Figure 5 summarises the significant rank correlation coefficients. Using the six volume measurements there were 15 possible combinations for rank correlation coefficients. Nine of the 15 pairs had a significant $r^{\prime}$, two pairs (VC sp versus FRC and VC TLC-RV versus TLC) were significant at $p<0.1$ but not $p<0.05$; and of the remaining four pairs with no significant correlation, three involved VC flows. Using the six flow measurements (FEF 25-75\%, Vmax TLC 70, Vmax TLC 50, Vmax TLC 40, Vmax VC 50, and Vmax VC 25), there were 15 possible pairs for determination of $r^{\prime}$. Twelve of the 15 had signifi. cant rank correlation coefficients $(p<0.05)$.

There was no significant correlation between the ranked SDs for volume measurements compared with flow measurements except when RV and TLC were compared with Vmax TLC 50, Vmax TLC 40, and Vmax VC 50. There was no significant correlation between SBNW and any of the other parameters.

\section{Discussion}

Comparison of sequential pulmonary function tests in the same individual can be used to assess progression of a disease, response to therapy, or response to bronchial provocation. These types of comparisons require an understanding of the factors influencing the variability normally seen in repeat measurements of lung function. Timing is one obvious factor. In these 20 healthy schoolchildren there was no significant change in variability caused by the time of day or the re-test interval up to a period of two months.

Assessment of variability in adults has shown similar results. McCarthy et al examined 44 adults 


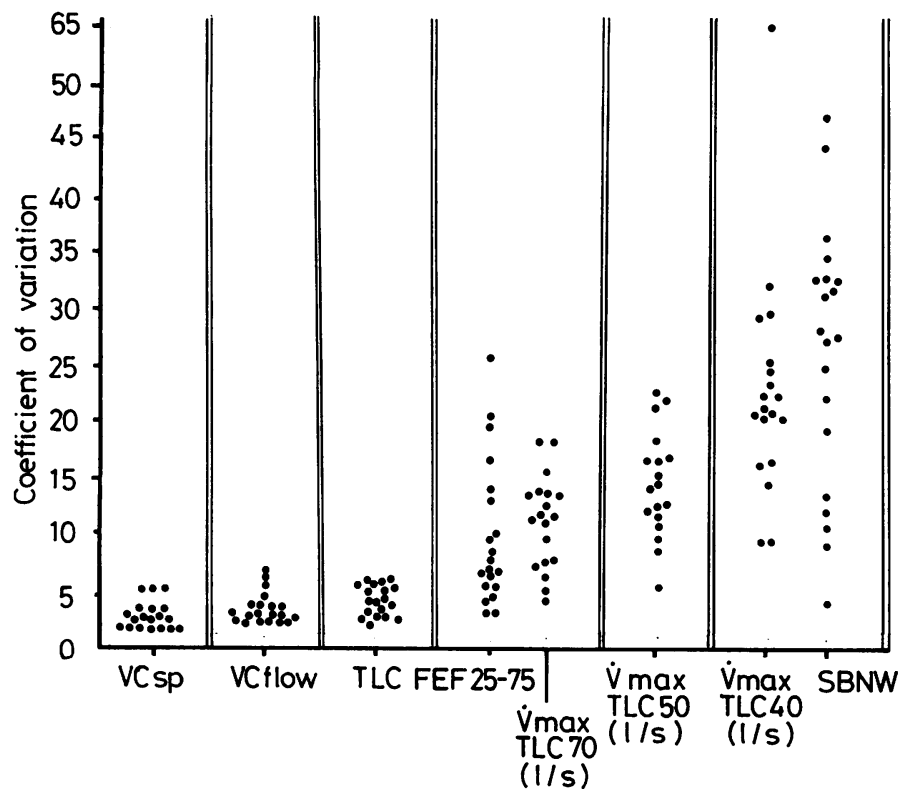

Fig 4 Each point represents the coefficient of variation for one subject for repeated measurements. Tests are arranged in order of increasing $\mathrm{CV} \%$ and are placed in six groups. Within a group there is no significant difference in $\mathrm{CV} \%$ but between groups there are significant differences $(p<0.05)$.

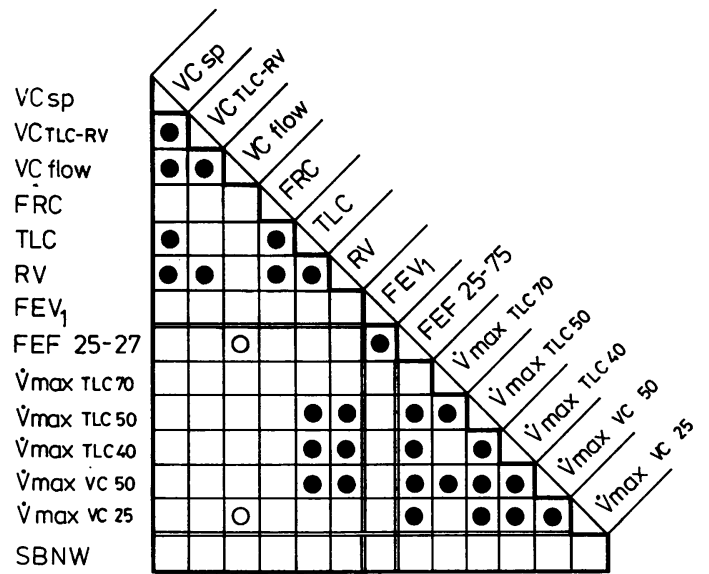

Fig 5 Summary of 91 pairs of SD with significance of the ranked correlation coefficient. Closed circles indicate significant $(p<0.05)$ positive $r^{\prime}$, open circles significant $(p<0.05)$ negative $r^{\prime}$ and blank spaces no significant correlation.

and found the variability of spirometry, SBNW and MEFV curves to be similar from hour-tohour, day-to-day, and week-to-week. ${ }^{3}$ Other reports confirm that time is not a significant factor in the reproducibility of pulmonary function tests in normal adults. ${ }^{13}{ }^{14}$ However, it must be emphasised that these studies were in healthy adults and covered a relatively short period of time: the longest test period examined was 28 weeks and most studies examined a period of six weeks or less. These figures, including those of the present study, do not concern themselves with changes which may occur after several months or years as a result of various factors such as growth, changing elastic properties of the lung, or environmental pollutants.

Leeder et al studied 19 schoolgirls on a weekly basis for five weeks and found that the variability of MEFV curve did not change significantly over the test period. ${ }^{15}$ The only exception was Vmax VC 50 which was significantly decreased in two girls after a lower respiratory tract infection. Geubelle and De Rudder ${ }^{16}$ measured FRC by helium washout and VC by spirometry in 23 healthy children. Triplicate measurements were made over a period of 13 days. They found no significant change in FRC over this time period but did find that the first VC determination was significantly higher than the second and third. They attributed this to lack of enthusiasm on the part of the child.

The SDs for each measurement can be helpful in deciding which tests are more appropriate for sequential measurements. In situations such as bronchial provocation where repeat tests are performed over a short period of time a test with a low degree and a small range of variability is required. $\mathrm{FEV}_{1}$, VCsp, and Vmax VC 25 appear to fill these criteria. 
It is more difficult to recommend a suitable parameter for studies covering a period of years. As other authors have suggested, the large variability of such tests as FEF $25-75 \%$, SBNW, and the flow-volume curve may reflect physiological differences in the population which may predispose them to pathological processes. ${ }^{3}$ Until the exact nature of these large differences in variability are fully understood it is difficult to select one group of tests over another for these long-term studies.

The SD of the population is a recognised measure of the variability. However, the coefficient of variation has also been used to quantitate the degree of variability. The coefficient is used when the standard deviation changes with the absolute size of the parameter measured. Therefore, $\mathrm{CV} \%$ is appropriate for a heteroscedastic scatter-that is, values of greater magnitude have larger variation-and SD is appropriate for a homoscedastic scatter - that is, the variation is independent of the magnitude of the value measured. Data are available on the intrasubject variability of pulmonary function tests in adults and it would appear that the scatter is homoscedastic. ${ }^{1718}$ However, the scatter of within-subject variability in children has not been delineated. The present sample of 20 healthy children aged 10 to 16 years is not large enough to determine confidently the nature of the scatter. However, using correlation coefficients, there was no correlation between the SDs and the absolute magnitude of the parameter measured for Vmax TLC 70, Vmax TLC 50, Vmax VC 50, VCsp, VCTLC-RV, VC flow, FEV 1 , FEF 25$75 \%$, and slope of phase III in SBNW. Towards the terminal portion of the flow-volume curvethat is, at TLC $40 \%$ and VC $25 \%$ there was a slight but significant correlation $(p<0.05)$ between the magnitude of the flow measurement and the SDs. Presumably, this occurs because the flows are approaching zero and a skewed distribution is obtained. There was a significant correlation $(\mathrm{p}<0.05)$ for RV, TLC, and FRC.

As intersubject variability in adults appears to be homoscedastic and since heteroscedasticity could not be demonstrated convincingly for intrasubject variability in these 20 children it was felt that SD should be used until a study on a larger number of randomly selected children assessed the type of scatter.

Comparing measurements of lung volume shows TLC, FRC, and RV to be more variable than measurements of VC. However, there is no significant difference in the SDs of these three lung volumes. This is in contrast with previous studies using $\mathrm{CV} \%$ which suggests that TLC is less vari- able and RV more variable. ${ }^{316}$ When the SDs are the same, dividing by mean TLC will give a small $\mathrm{CV} \%$ for TLC and dividing by mean RV will give a large $\mathrm{CV} \%$ for $\mathrm{RV}$.

Examination of the flow-volume curves shows a similar problem. It is generally felt that the initial part of the MEFV curve is effort-dependent and the latter part effort-independent. ${ }^{19}$ It would seem reasonable to hypothesise that the effortdependent part would be more variable and the effort-independent less variable. However, previous studies give conflicting results. ${ }^{317}$ In this study, the variability as defined by the SDs is the same for Vmax TLC 70, Vmax TLC 50, Vmax VC 50, and Vmax TLC 40.

However, at VC 25\% an interesting phenomenon occurs. The SDs for Vmax VC 25 are significantly $(\mathrm{p}<0.05)$ less than the two points (Vmax TLC 50 and Vmax TLC 40) on either side of VC $25 \%$. Superimposing the flow-volume curves of one child (fig 6) demonstrated this phenomenon. One possible explanation is that differences in inspiratory effort cause differences in VC and the flows measured at divisions of TLC might be affected more than the flows measured at divisions of VC which could partially be compensated by similar changes in VC. However, if this were the case, one would expect Vmax VC50 to act similarly to Vmax VC 25 which it does not. Furthermore, if the variability were somehow related to changes in VC flow, a person with a large variability in VC flow would have a large variability in flows which was not the case (fig 5). A second more likely possibility, is that VC $25 \%$ is the junction point between the last two parts of the three part flow volume curve described by Mead et al. ${ }^{20}$ The

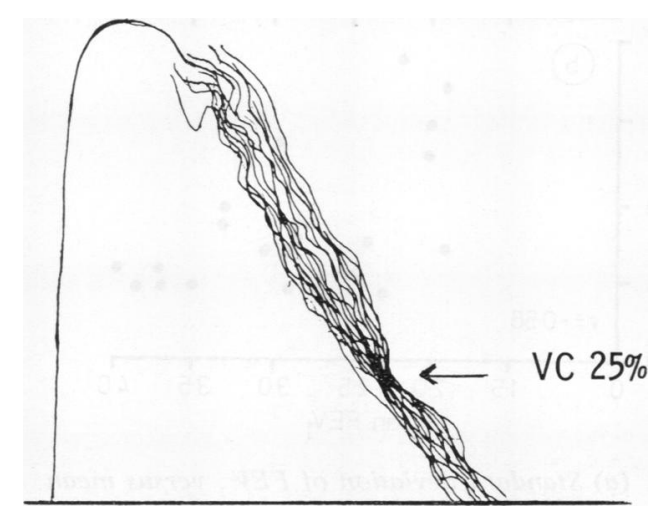

Fig 6 Flow-volume curves superimposed (at TLC) in one child demonstrating the decreased variability of $V C 25 \%$. 
first segment which is at high lung volumes is effort-dependent. Near the point where $25 \%$ of the vital capacity is expired, the equal pressure point becomes fixed and the flows generated become independent of effort and hence flows may have equal variability. This represents the second segment. The third segment begins at lung volumes less than VC $25 \%$-that is, TLC $40 \%$ and lower -where the effort-dependent factors determining RV come into play. In young people the terminal portion of the flow volume curve may be limited by the chest wall "giving up." In an older individual dynamic factors in the lung such as airway closure may play a limiting role. In some subjects, especially younger ones, a balance between these two limiting factors occurs which can change from blow to blow caused by changes in motivation, strength, fatigue, and learning. ${ }^{21}$ TLC $40 \%$ may represent the point where these limiting factors determining RV become important. Because a variation in the balance of the factors can be seen in an individual, Vmax TLC 40 would vary according to the balance.

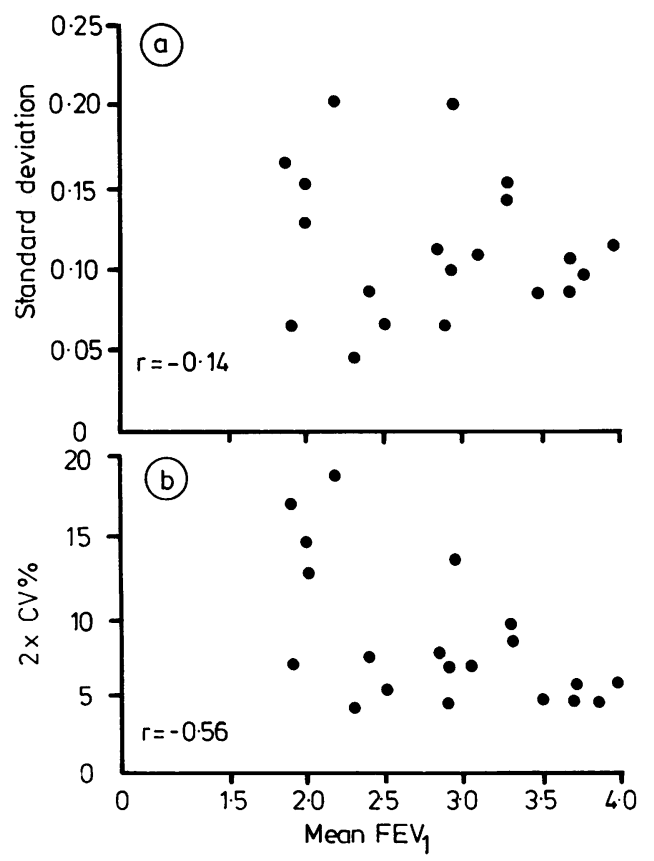

Fig 7 (a) Standard deviation of FEV, versus mean $F E V_{1}$ showing no significant correlation $(r=0 \cdot 14)$. (b) $2 \times$ coefficient of variation for $F E V_{1}$ versus mean $F E V_{1}$ showing a significant $(r=-0.56, p<0.05)$ negative correlation.
Bronchial provocation testing requires the ability to separate normal intrasubject variability on repeat testing from abnormal bronchial reactivity. One recognised method is to accept a $20 \%$ decrease in FEV $_{1}$ as significant. ${ }^{22}$ It is not clear why the percent change rather than an absolute change is used. Perhaps it was argued that a short person with a small baseline $\mathrm{FEV}_{1}$ had less potential for change than a tall person with a large $\mathrm{FEV}_{1}$. Whatever the original reason, using percent change in $\mathrm{FEV}_{1}$ requires a greater absolute change for a large $\mathrm{FEV}_{1}$ compared with a small $\mathrm{FEV}_{1}$ to reach significance. However, in these normal schoolchildren with range of $\mathrm{FEV}_{1}$ between 1.9 and 4.0 , the SDs for repeat measurements of $\mathrm{FEV}_{1}$ were independent of the absolute value of $\mathrm{FEV}_{1}$ (fig 7a). An approximation of the $95 \%$ limit for $\mathrm{FEV}_{1}$ due to intrasubject variability expressed in percent would be $2 \mathrm{SD} /$ mean $\mathrm{FEV}_{1}$ $\times 100 \%(2 \times \mathrm{CV} \%)$. A graph of $2 \times \mathrm{CV} \%$ against mean $\mathrm{FEV}_{1}$ (fig 7b) shows a significantly higher

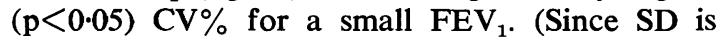
approximately the same for all $\mathrm{FEV}_{1}$, dividing by a small $\mathrm{FEV}_{1}$ gives a higher $\mathrm{CV} \%$ than dividing by a larger $\mathrm{FEV}_{1}$.) In other words, for a healthy population the smaller the $\mathrm{FEV}_{1}$ the greater was the percent variability about the mean. Using SDs the intrasubject variability about the mean is independent of the absolute value of the mean $\mathrm{FEV}_{1}$ - that is, a homoscedastic scatter. It seems reasonable to suggest that the criterion for positive bronchial reactivity be reassessed. Absolute change may be more appropriate than percent change.

The analysis using multiple rank correlation coefficients suggests that a significant portion of the intrasubject variability is the result of physiological changes. If the reproducibility was affected mainly by technical and mechanical factors it is likely that the variability would be random. However, this was not the case, and the children who had more variable flows at different points of the MEFV curves were also more variable on the spirometric determination of flow (FEF 25-75\%). A similar, but less significant pattern was seen when comparing measurements of volume. SBNW was a unique parameter as its variability did not correlate with any of the other tests.

Because of this slight association between the variability of lung volumes, and the separate stronger association between measurements of flow, it is hypothesised that these measurements are determined by different controlling factors. This hypothesis would make an attractive corollary to the concept of dysanaptic growth proposed by Green et al. ${ }^{23}$ They suggested that there could be 
physiological variation between airways and lung tissue caused by different patterns of embryonic growth.

The critical analysis of the manuscript by $\mathrm{Dr} A$ Olinsky and the secretarial assistance of $\mathbf{J}$ Matheson are acknowledged gratefully.

\section{References}

1 Clément J, van de Woestijne KP. Variability of maximum expiratory flow-volume curves and effort independency. J Appl Physiol 1971; 31: 55-62.

2 Macklem PT, Mead J. The physiological basis of common pulmonary function tests. Arch Environ Health 1967; 14:5-9.

3 McCarthy DS, Craig DB, Cherniak RM. Intraindividual variability in maximum expiratory flow-volume and closing volume in asymptomatic subjects. Am Rev Respir Dis 1975; 112:407-11.

4 Buist AS, Ross BB. Quantitative analysis of the alveolar plateau in the diagnosis of early airway obstruction. Am Rev Respir Dis 1973; 108:107887.

5 Fowler WS. Lung function studies. III Uneven pulmonary ventilation in normal subjects and in patients with pulmonary disease. J Appl Physiol 1949-50; 2:283-99.

6 Mills RJ, Harris P. Factors influencing the concentration of expired nitrogen after a breath of oxygen. J Appl Physiol 1965; 20:103-9.

7 American Thoracic Society-Snowbird workshop on standardization of spirometry. Am Rev Respir Dis 1979; 119:831-8.

8 DuBois AB, Botelho SY, Bedell GN, Marshall $\mathrm{R}$, Comroe JH Jr. A rapid plethysmographic method for measuring thoracic gas volume; a comparison with a nitrogen washout method for measuring functional residual capacity in normal subjects. J Clin Invest 1956; 35:322-6.

9 Anthonisen NR, Danson J, Robertson PC, Ross WRD. Airway closure as a function of age. Respir Physiol 1969; 8:58-65.
10 Cook CD, Hamann JF. Relation of lung volumes to height in healthy persons between the ages of 5 and 38 years. $J$ Pediatr 1961; 59:710-4.

11 Polgar G, Promadhat V. Pulmonary function testing in children: techniques and standards. Philadelphia: WB Saunders, 1971.

12 Snedecor GW, Cochran WG. Statistical methods. Sixth edition. The Iowa State University Press, 1967.

13 Becklake MR, Leclerc M, Strobach H, Swift J. The $\mathrm{N}_{2}$ closing volume test in population studies: sources of variation and reproducibility. Am Rev Respir Dis 1975; 111:141-7.

14 Cochrane GM, Prieto F, Clark TJH. Intrasubject variability of maximal expiratory flow volume curve. Thorax 1977; 32:171-6.

15 Leeder SR, Swan AV, Peat JK, Woolcock AJ, Blackburn CRB. Maximum expiratory flowvolume curves in children: changes with growth and individual variability. Bull Europ Physiopathol Respir 1977; 13:249-60.

16 Geubelle F, De Rudder P. Respiratory studies in children III. Variability of lung volume in healthy children. Acta Paediatr 1961; 50:595-602.

17 Sobol BJ, Emirgil C. Subject effort and the expiratory flow rate. Am Rev Respir Dis 1964; 89: 402-8.

18 Sobol BJ, Sobol PG. Percent of predicted as the limit of normal in pulmonary function testing: a statistically valid approach. Thorax $1979 ; 34: 1-30$.

19 Hyatt RE, Schilder DP, Fry DL. Relationship between maximum expiratory flow and degree of lung inflation. J Appl Physiol 1958; 13:331-6.

20 Mead J, Turner JM, Macklem PT, Little JB. Significance of the relationship between lung recoil and maximum expiratory flow. J Appl Physiol 1967; 22:95-108.

21 Leith DE, Mead J. Mechanisms determining residual volume of the lungs in normal subjects. J Appl Physiol 1967; 23:221-7.

22 Chai H, Farr RS, Froehlich LA et al. Standardisation of bronchial inhalation challenge procedures. J Allergy Clin Immunol 1975; 56:323-7.

23 Green M, Mead J, Turner JM. Variability of maximum expiratory flow-volume curves. J A ppl Physiol 1974; 37:67-74. 